\title{
Ependymal restricted diffusion and injury to the olfactory system on a ventriculoencephalitis associated with COVID-19
}

\author{
Americo Danúzio Pereira Oliveira ${ }^{1}$ (1) $\cdot$ Ana Rosa Melo Corrêa Lima ${ }^{2} \cdot$ Maria de Fátima Viana Vasco Aragao ${ }^{3,4}$
}

Received: 5 July 2021 / Revised: 3 November 2021 / Accepted: 27 November 2021 / Published online: 4 January 2022

(c) Journal of NeuroVirology, Inc. 2022

\begin{abstract}
We describe the case of a 42-year-old female with COVID-19 and acute psychomotor agitation and without comorbidities. Brain MRI showed injury to the olfactory system associated with diffusion weighted imaging restriction in the ependymal surface of the lateral ventriculus suggesting ventriculoencephalitis.
\end{abstract}

Keywords Ventriculoencephalitis · Olfactory bulb · COVID-19

\section{Introduction}

There is growing evidence that severe acute respiratory syndrome coronavirus 2 (SARS-Cov 2) not only affects the respiratory tract but also influences the central nervous system (CNS). Neurological manifestations of infectious diseases may be nonspecific, so imaging is essential in reaching a diagnosis and helps in coming to a therapeutic decision (Kremer et al. 2020). This brief report describes the case of a COVID-19 ventriculoencephalitis with injury to the olfactory system and diffusion weighted imaging restriction in the ependymal surface of the lateral ventricles.

\section{Case report}

A 42-year-old female was admitted after six 6 of symptoms of upper airway infection with acute psychomotor agitation. Her previous history was negative for comorbidities or immunodeficiency. On neurological examination, she was awake and disoriented. Her short-term memory, delayed recall, and ability to perform complex task and multistep

Americo Danúzio Pereira Oliveira americo.oliveira@upe.br

1 University of Pernambuco, Serra Talhada, Brazil

2 University of Pernambuco (UPE), Recife, Brazil

3 University Federal of Pernambuco (UFPE), Recife, PE, Brazil

4 Multimagem, Recife-PE, Brazil commands were compromised. She was isochoric, and without nuchal rigidity. Symmetrical motor response to painful stimuli and bilateral flexor plantar response were present. The following day, the patient developed fever $\left(\mathrm{t}=38,7^{\circ} \mathrm{C}\right)$ and dyspnea with decreased oxygen saturation (Sat $\mathrm{O} 2=88 \%$ ), which improved with oxygen therapy by mask. Impairment in anterograde memory with relative preservation of verbal fluency and autobiographical memory were observed. Blood investigation showed elevated D-dimer $(3020 \mu \mathrm{g} / \mathrm{dl})$, C-reactive protein $(>9.0 \mathrm{mg} / \mathrm{dl})$, and creatine phosphokinase $(1565 \mathrm{U} / \mathrm{L})$. Other routine blood tests, including renal and liver test, were normal. The RT-PCR test on nasopharyngeal swab detected SARS-CoV-2. The chest $\mathrm{CT}$ scans showed ground-glass opacity in both lungs.

On the second day of admission, therefore the seventh day of onset of flu-like symptoms, MRI, and cerebrospinal fluid (CSF) were performed. Brain MRI showed diffuse hyperintense lesions on $\mathrm{T} 2$ and fluid-attenuated inversion recovery (FLAIR) especially affecting the ependymal surface of the lateral ventricles, notably the ventricular trigones and posterior horns, in addition to the white matter of the mesial temporal lobes and frontal-basal bilateral regions without contrast enhancement. The lesions along the ventricular wall were hyperintense on diffusion weighted imaging (DWI) and hypointense on apparent diffusion coefficient Map (ADCMap). The coronal pre- and post-contrast T1-weighted imaging show that the olfactory bulbs have an abnormal enhancement and become hyperintense (Fig. 1).

CSF examination showed acellular (white and red cell count $\left.0.00 / \mathrm{mm}^{3}\right)$, high protein $(250 \mathrm{mg} / \mathrm{dl})$, and normal glucose $(65 \mathrm{mg} / \mathrm{dl})$. Gram stain and bacterial and fungi culture 


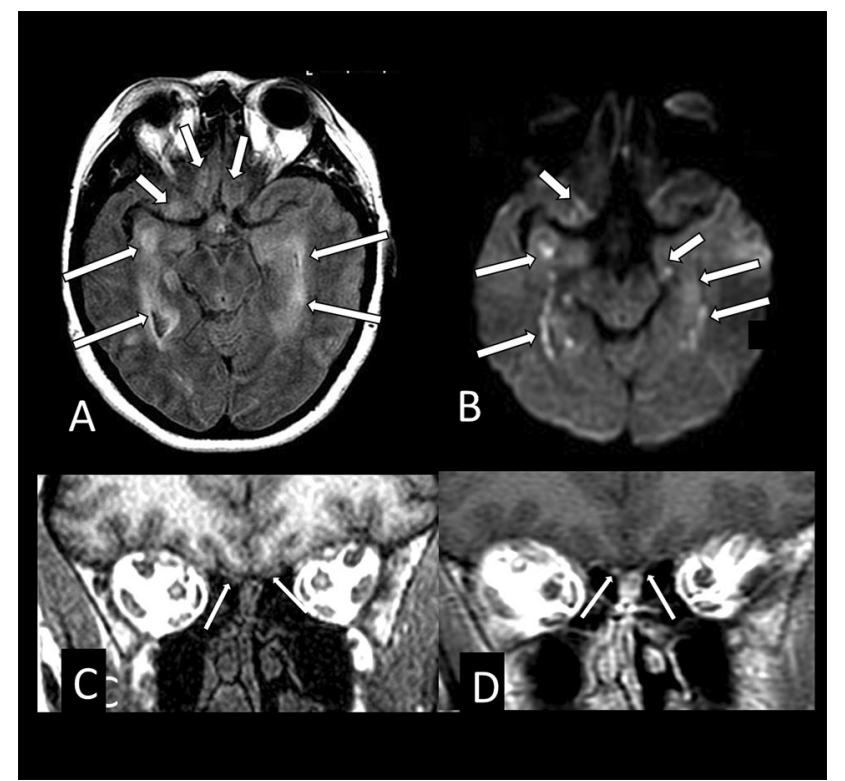

Fig. 1 The brain MRI showshyperintense lesions on axial FLAIR (A, arrows) and on axial diffusion (B,arrows) located at the posterior portion ofrectus gyri, the wallsofthesupratentorialventricles(tempo ral hornsshowed), uncus and parahippocampalgyri. The coronal precontrast T1WI (C) and post contrast T1 WI(D) shows that there are injuries of theolfactory bulbs which represent enhancement on post contrast T1 WI (D, arrows)

were negative. PCR was negative for cytomegalovirus (CMV), herpes simplex virus 1, and 2 and SARS-CoV-2.

A patient was treated with non-invasive respiratory management, subcutaneous heparin, ceftriaxone, and oral azithromycin. After MRI and CSF results, intravenous Immunoglobulin $(0.4 / \mathrm{kg}$ daily over five days) was started, followed by high doses of intravenous pulses of methylprednisolone (1 g/daily over three days). After steroid treatment, her mental status improved, despite persisting mild episodic memory impairment. She was discharged after 2 weeks.

\section{Discussion}

We describe a ventriculoencephalitis characterized by acute development of confusion and short-term memory in a COVID-19 patient. Encephalitis and encephalopathy were described on COVID-19 with variable neurological symptoms and radiologic findings (Kremer et al. 2020; Pizzanelli et al. 2021). In this context, brain MRI could be an important tool to aid in making decisions to guide treatment, particularly if microbiology tests were delayed. In this case, MRI showed injury to the orbitofrontal cortex and diffusion restriction on ependymal surface without contrast enhancement.
Diffuse lesions hyperintense on DWI and T2/FLAIR observed in this case could be explained by a high expression of the ACE2 receptor in the central nervous system (CNS), in particular in the choroid plexus, ventricles, middle temporal gyrus, posterior cingulate cortex, and olfactory bulb (Uversky et al. 2021). The injuries of the olfactory bulbs and primary olfactory cortex could represent one possible route of neuroinvasive entry via the olfactory nerve, infection of vascular endothelium, or leukocyte migration across the blood-brain barrier (Aragão et al. 2020). Abnormal enhancing post-contrast T1-weighted images on orbitofrontal cortex are shown (Aragão et al. 2020), but the concomitant diffusion-weighted restriction of ependyma are not. Acute leukoencephalopathy described usually in critically ill cases of severe acute respiratory syndrome (SARS) could be associated with late complications in secondary hypoxemia (Radmanesh et al. 2020). However, our patient remained responsive throughout the period of low oxygen saturation and did not need mechanical ventilation.

The supratentorial ependymal restricted diffusion weighted imaging (DWI) lesions were described in other neuroinfectious diseases, like CMV ventriculitis (Seok et al. 2011). Restricted diffusion lesions were also shown in COVID-19 patients, especially cytotoxic lesion of the corpus callosum (CLOCC) (Kremer et al. 2020), but not with involvement of the lateral ventriculus walls as is observable. The restricted diffusion could be explained by direct viral invasion and intra-cellular multiplication. However, in this case CSF PCR SARS- CoV-2 was negative, while detection of SARS-CoV-2 in CSF via PCR appears to be rare (Lewis et al. 2021), indicating that viral clearance precedes the neurological involvement. We hypothesized that brain injuries were secondary to a hyperinflammation syndrome. It can be, perhaps, determined by a cytokine storm that triggers $\mathrm{T}$ cells to breach the blood-brain barrier causing inflammation, an indirect process resulting from hypercoagulability-related thrombus formation (Shi et al. 2020) or multifocal microvascular injury in the brain (Lee et al. 2021).

\section{Conclusion}

We present a case of ventriculoencephalitis in COVID-19, a novel finding in COVID-19 patients. As we did not have access to the COVID-19 serotype, we cannot determine whether this finding is more specific to the new Brazilian variant of the COVID-19 (Plante et al. 2021). In this ventriculoencephalitis case, the simultaneity of the orbitofrontal cortex and olfactory bulb injuries could be an important clue regarding COVID-19. In the future, case series would show whether these findings could represent a pattern on the COVID-19 disease. 


\section{Declarations}

Conflict of interest The authors declare no competing interests.

\section{References}

Aragão MD, Leal MC, Cartaxo Filho OQ, Fonseca TM, Valença MM (2020) Anosmia in COVID-19 Associated with Injury to the Olfactory Bulbs Evident on MRI. AJNR Am J Neuroradiol 41(9):1703-1706. https://doi.org/10.3174/ajnr.A6675. Epub 2020 Jun 25. PMID:32586960;PMCID:PMC7583088

Kremer S, Lersy F, Anheim M, Merdji H, Schenck M, Oesterlé H, Bolognini F, Messie J, Khalil A, Gaudemer A, Carré S (2020) Neurologic and neuroimaging findings in patients with COVID19: A retrospective multicenter study. Neurology 95(13):e1868e1882. https://doi.org/10.1212/WNL.0000000000010112. Epub 2020 Jul 17 PMID:32680942

Lee MH, Perl DP, Nair G, Li W, Maric D, Murray H, Dodd SJ, Koretsky AP, Watts JA, Cheung V, Masliah E, Horkayne-Szakaly I, Jones R, Stram MN, Moncur J, Hefti M, Folkerth RD, Nath A (2021) Microvascular Injury in the Brains of Patients with Covid-19. N Engl J Med 384(5):481-483. https://doi.org/10.1056/ NEJMc2033369. Epub 2020 Dec 30. PMID:33378608;PMCID: PMC7787217

Lewis A, Frontera J, Placantonakis DG, Lighter J, Galetta S, Balcer L, Melmed KR (2021) Cerebrospinal fluid in COVID-19: A systematic review of the literature. J Neurol Sci. 421:117316. https://doi. org/10.1016/j.jns.2021.117316. Epub 2021 Jan 10. PMID:33561 753;PMCID:PMC7833669
Pizzanelli C, Milano C, Canovetti S, Tagliaferri E, Turco F, Verdenelli S, Nesti L, Franchi M, Bonanni E, Menichetti F, Volterrani D, Cosottini M, Siciliano G (2021) Autoimmune limbic encephalitis related to SARS-CoV-2 infection: Case-report and review of the literature. Brain Behav Immun Health 12:100210. https://doi.org/ 10.1016/j.bbih.2021.100210. Epub 2021 Jan 24. PMID:3352169 1;PMCID:PMC7830195

Plante JA, Mitchell BM, Plante KS, Debbink K, Weaver SC, Menachery VD (2021) The variant gambit: COVID-19's next move. Cell Host Microbe 29(4):508-515. https://doi.org/10.1016/j.chom.2021.02. 020. Epub 2021 Mar 1. PMID:33789086;PMCID:PMC7919536

Radmanesh A, Derman A, Lui YW, Raz E, Loh JP, Hagiwara M, Borja MJ, Zan E, Fatterpekar GM (2020) COVID-19-associated Diffuse Leukoencephalopathy and Microhemorrhages. Radiology 297(1):E223-E227. https://doi.org/10.1148/radiol.2020202040. Epub 2020 May 21. PMID:32437314;PMCID:PMC7507998

Seok JH, Ahn K, Park HJ (2011) Diffusion MRI findings of cytomegalovirus-associated ventriculitis: a case report. Br J Radiol 84(1005):e179-e181. https://doi.org/10.1259/bjr/31561378

Shi W, Lv J, Lin L (2020) Coagulopathy in COVID-19: Focus on vascular thrombotic events. J Mol Cell Cardiol 146:32-40. https:// doi.org/10.1016/j.yjmcc.2020.07.003. Epub 2020 Jul 15. PMID: 32681845;PMCID:PMC7362808

Uversky VN, Elrashdy F, Aljadawi A, Ali SM, Khan RH, Redwan EM (2021) Severe acute respiratory syndrome coronavirus 2 infection reaches the human nervous system: How? J Neurosci Res 99(3):750-777. https://doi.org/10.1002/jnr.24752

Publisher's Note Springer Nature remains neutral with regard to jurisdictional claims in published maps and institutional affiliations. 